\title{
Muscular activity and energy expenditure: biochemistry and physiology of exercising muscle A report of The Rank Prize Funds Mini-Symposium 1990
}

\author{
M. J. Dauncey ${ }^{1}$ and K. L. Blaxter ${ }^{2}$
}

At a meeting organized by The Rank Prize Funds, a small group of invited young research scientists discussed their work on muscular activity and energy expenditure with some more senior people. An account of those aspects of the meeting which dealt with methodology, factors influencing energy expenditure and possible differences in the mechanical efficiency of muscular activity have been discussed elsewhere ${ }^{1}$. The present account concentrates on papers concerned with the mechanism of muscular contraction, particularly in relation to exercise and fatigue. Key references suggested by the participants have been incorporated in the text.

Biochemistry and biophysics of contraction A general introduction to the biochemistry and biophysics of the contraction process was presented and an explanation given as to why less force is developed during shortening than in isometric contraction ${ }^{2,3}$. Attention was drawn to differences between current understanding and the general accounts of contraction in standard textbooks and it was pointed out, for example, that not all cycles of attachment and detachment of cross-bridges lead to the splitting of ATP. Some recent findings on the energetic cost of work production were presented by $\mathbf{C}$. Yin, in collaboration with R.C. Woledge, who contrasted results from frog and mouse. It was concluded that an unknown process must occur during or after a working contraction in mouse soleus muscle and that this probably explains its higher energetic cost of work production compared with frog muscle. Evidence supporting the idea of 'unexplained heat' during a contraction and its related

${ }^{1}$ Department of Cell Biology, AFRC Institute of Animal Physiology and Genetics Research,

Babraham, Cambridge CB2 4AT and ${ }^{2}$ The Rank Prize Funds, Warwick Square, London SW1V $2 A A, U K$

Address for correspondence: Dr. M.J. Dauncey

(C) 1991 Butterworth-Heinemann Ltd. 0306-3674/91/010002-02 recovery process in mammalian muscle was provided by S.K. Phillips. Use of ${ }^{31} \mathrm{P}$ NMR showed a difference between the time course of recovery heat and the resynthesis of phosphocreatine from inorganic phosphate and such findings extend the results of earlier reports ${ }^{4}, 5$.

Novel findings were presented by $\mathbf{P}$. Bolger, in collaboration with A. Rowe, on the effect of divalent cation on the cross-bridges of vertebrate skeletal muscle thick filaments. The presence of non-specific low affinity divalent cation binding sites had been demonstrated in synthetic myosin filaments ${ }^{6}$ and such sites have now been demonstrated in purified native myosin filaments. It appears that the elasticity of the cross-bridges can be altered by an interaction between the low and high affinity sites in such a way as to make them more elastic as the muscle becomes activated. This may in turn alter the interaction kinetics ${ }^{7}$ and hence provide another form of regulation in addition to the actin-linked steric-hindrance system. New approaches which should advance our understanding of the molecular mechanism of muscular contraction were discussed by K.J.V. Poole. Studies in collaboration with G. Rapp and R.S. Goody have been concerned with dynamic X-ray diffraction measurements following photolytic relaxation and activation of mammalian muscle fibres. Of particular interest is the location of strain-sensitive rates in the cross-bridge cycle since these will reflect the important energy transducing steps in the muscle ATPase mechanism. The time course of changes in the equatorial diffraction patterns from different muscle types on photolysis of caged-ATP has been examined using the DESY synchrotron source in Hamburg ${ }^{8,9}$. Some of the implications of such investigations have been discussed previously by Huxley ${ }^{10}$.

\section{Muscle fatigue}

Skeletal muscle fatigue can be defined as a failure to maintain force or power output $^{11}$ and numerous investigations have been concerned with elucidating its mechanisms. A general introduction to the problem of fatigue was presented by E.A. Newsholme and this was followed by two presentations on its physiology. An interesting hypothesis based on studies of human adductor pollicis suggests that the extra potentiation and reduced fatigability at low stimulation frequencies, when preceded by high frequency, is the result of increased myofibrillar $\mathrm{Ca}^{2+}$ availability and/or sensitivity ${ }^{12}$. Alterations in force dynamics in fatigued muscle were discussed by $\mathbf{C}$.J. Barclay who advanced a scheme to account for the observed changes in isometric force and force dynamics that occur in fatigued mouse muscle. Results were discussed in relation to earlier studies on muscle contraction and fatigue ${ }^{13,14}$.

A significant finding was reported in relation to exercise-induced hyperkalaemia and fatigue in man: regular training increases the concentration of $\mathrm{Na}^{+}, \mathrm{K}^{+}$-pumps in vastus lateralis muscle ${ }^{15}$. This could help to explain the reduction in exercise-induced hyperkalaemia associated with training. Beneficial effects of training could thus arise, not only because hyperkalaemia is associated with fatigue and is detrimental to physical performance but also because the less pronounced hyperkalaemia will reduce the risk of the cardiotoxic effects of exercise. Evidence for the role of specific amino acids in relation to fatigue was reviewed in relation to its aetiology and the overtraining syndrome in athletes ${ }^{16}$. This led to a consideration of plasma glutamine concentration as an important link between skeletal muscle and cells of the immune system during exercise. These cells use glutamine at very high rates and this is essential for lymphocyte proliferation ${ }^{17}$. A decrease in plasma glutamine concentration may thus result in impairment of immune function and in overtraining syndrome there is indeed an increased incidence of viral infection. The possibility is that regulation of plasma glutamine levels occurs at the point of its release from 
the muscle cell membrane and it has been found that plasma levels are lower in athletes after long-term exercise or at rest in overtrained subjects.

\section{Exercising muscle}

Further aspects of the biochemistry of exercising muscle were considered in relation to intracellular acidosis and nucleotide loss in the human and equine athlete ${ }^{18-20}$. Studies on high intensity exercise indicate that there is a threshold to the start of adenine nucleotide loss which corresponds to a given fall in $\mathrm{pH}$ and accumulation of lactate above a given level. This loss of adenine nucleotide occurs mainly as ATP and the extent of its fall appears to be reduced by administration of sodium bicarbonate ${ }^{21}$. Other investigations were concerned with the effects of training on muscle metabolism during treadmill sprinting and recovery 22,23 . For example, 8 weeks of sprint training was found to result in a $12 \%$ improvement in peak power output and this was accompanied by an increase in post-exercise muscle lactate and a decrease in post-exercise blood $\mathrm{pH}$. There was, however, no further change in the post-exercise muscle $\mathrm{pH}$ or its buffering capacity, and the possibility is that $\mathrm{H}^{+}$efflux could be enhanced by sprint training. Consideration was also given to the influence of nutrition on muscle metabolism and performance during high intensity exercise. It was reported, for example, that changes in muscle $\mathrm{pH}$ and glucose 6-phosphate are greater during a fixed period of high intensity exercise after a low carbohydrate, high fat, high protein diet than after a high carbohydrate diet ${ }^{24}$

The use of a non-invasive method for assessing whole muscle glycogen stores was discussed by A.M. Prentice. This method uses indirect calorimetry and obviates the need for muscle biopsies. Its value for investigating high intensity exercise remains to be determined. Glycogen availability is not at present considered to be a limiting factor for the performance of high intensity exercise, since whole muscle glycogen levels are high at the point of fatigue. However, important new evidence suggests that the use of whole muscle substrate and metabolite levels as indicators of the metabolic response to high intensity exercise could be misleading because of a marked difference in response between fibre types ${ }^{25}$. Previous investigations have suggested that skeletal muscle is an important thermogenic organ in $\operatorname{man}^{26}$. This hypothesis was not supported by results on adrenaline-induced oxygen consumption in forearm skeletal muscle presented by I.W. Gallen. However, these results remain to be confirmed by direct measurement of muscle oxygen consumption in various sites. The possi- bility also exists that there could be a differential response between fibre types and this suggestion remains to be investigated.

The symposium provided an excellent opportunity for bringing together individuals with a wide range of research interests. Not only did it provoke exciting discussion and exchange of ideas but it also highlighted important new areas for research.

\section{Acknowledgements}

We thank Sir John Davis CVO and the Trustees of The Rank Prize Funds for their generous support of this symposium and without whom there would have been no meeting. We should also like to thank Miss Judith Barnes and Miss Emma Croker for all their help in organizing the meeting and Mrs Julie Brown for her invaluable assistance.

\section{References}

1 Dauncey MJ, Blaxter KL. Muscular activity and energy expenditure: energetic efficiency and the influence of genetics and environment. Eur I Clin Nutr 1991; (in press).

2 Woledge RC, Curtin NA, Homsher E. Energetic Aspects of Muscle Contraction. Monograph No. 41 of the Physiological Society. San Diego, California: Academic Press; Harcourt Brace Jovanovich, 1985.

3 Woledge RC. Energy transformation in living muscle. In: Weiser W, Gnaiger $\mathrm{E}$, eds. Energy Transformations in Cells and Organisms. Proceedings of the 10th Conference of the European Society for Comparative Physiology and Biochemistry. Stuttgart and New York: Thieme 1989: 36-45.

4 Gower D, Kretzchmar KM. Heat production and chemical change during isometric contraction of rat soleus muscle. J Physiol 1976; 258: 659-71.

5 Crow MT, Kushmerick MJ. Chemical energetics of slow- and fast-twitch muscles of the mouse. J Gen Physiol 1982; 79: 147-66.

6 Persechini A, Rowe AJ. Modulation of myosin filament conformation by physiological levels of divalent cation. J Mol Biol 1984; 172: 23-39.

7 Farrow AJ, Rossmanith GH, Unsworth J. The role of calcium ions in the activation of rabbit psoas muscle.J Musc Res Cell Motility 1988; 9: 261-74.

8 Poole KJV, Rapp G, Maeda Y, Goody RS. The time course of changes in the equatorial diffraction patterns from different muscle types on photolysis of caged ATP. In: Sugi H, Pollack G, eds. Molecular Mechanism of Muscle Contraction New York and London: Plenum, 1988: 391-404.

9 Poole KJV, Rapp G, Maeda Y, Goody RS. Synchrotron radiation studies on insect flight muscle. Top Curr Chem 1988; 47: 1-29.

10 Huxley A. Muscular contraction. Ann Rev Physiol 1988; 50: 1-16.

11 Edwards RHT. Human muscle function and fatigue. In: Porter J, Whelan $\mathrm{R}$, eds. Human Muscle Fatigue: Physiological Mechanisms, Ciba Foundation
Symposium No. 82, London: Pitman Medical, 1981: 1-18.

12 Gibson H, Cooper RG, Stokes MJ, Edwards RHT. Mechanisms resisting fatigue in isometrically contracting human skeletal muscle. Q J Exp Physiol 1988; 73: 903-14.

13 Jones DA, Bigland-Ritchie B, Edwards RHT. Excitation frequency and muscle fatigue: mechanical responses during voluntary and stimulated contractions. Exp Neurol 1979; 64: 401-13.

14 Cooke, R, Franks K, Luciani GB, Pate E. The inhibition of rabbit skeletal muscle contraction by hydrogen ions and phosphate. J Physiol 1988; 395: 77-97

15 Klitgaard $\mathrm{H}$, Clausen $\mathrm{T}$. Increased total concentration of Na-K pumps in vastus lateralis muscle of old trained subjects. I Appl Physiol 1989; 67: 2491-4.

16 Parry-Billings $\mathrm{M}$ Blomstrand $\mathrm{E}$ McAndrew N, Newsholme EA. A communicational link between skeletal muscle, brain and cells of the immune system. Int J Sports Med 1990; 11: S122-8.

17 Szondy Z, Newsholme EA. The effect of glutamine concentration on the activity of carbamoyl-phosphate synthase II and on the incorporation of $\left[{ }^{3} \mathrm{H}\right]$ thymidine into DNA in rat mesenteric lymphocytes stimulated by phytohaemagglutinin. Biochem J 1989; 261: 979-89.

18 Snow DH, Harris RC, Gash SP Metabolic response of equine muscle to intermittent maximal exercise. Appl Physiol 1985; 58: 1689-97.

19 Cheetham ME, Boobis LH, Brooks S, Williams C. Human muscle metabolism during sprint running. $J A p p l$ Physiol 1986; 61: 54-60.

20 Harris RC, Marlin DJ, Snow DH Harkness RA. Muscle ATP loss and lactate accumulation at different work intensities in the exercising thoroughbred horse. Eur J Appl Physiol 1991; (in press).

21 Greenhaff PL, Harris RC, Snow DH The effect of sodium bicarbonate administration upon exercise metabolism in the thoroughbred horse. I Physiol 1990; 420: 69P.

22 Nevill ME, Boobis LH, Brooks S, Williams C. Effect of training on muscle metabolism during treadmill sprinting. J Appl Physiol 1989; 67: 2376-82.

23 Allsop $\mathrm{P}$, Cheetham ME, Brooks S Hall GM, Williams C. Continuous intramuscular $\mathrm{pH}$ measurement during recovery from brief maximal exercise in man. Eur I Appl Physiol 1990; 59: 465-70.

24 Greenhaff PL, Gleeson M, Maughan RJ. The effects of diet on muscle $\mathrm{pH}$ and metabolism during high intensity exercise. Eur J Appl Physiol 1988; 57: 531-9.

25 Greenhaff PL, Ren J-M, Soderlund K Hultman E. Energy metabolism in type I and type II human muscle fibres during electrical stimulation and epinephrine infusion. Am I Physiol 1991; (in press).

26 Astrup A, Bulow J, Christensen NJ Madsen J, Quaade F. Facultative thermogenesis induced by carbohydrate: a skeletal muscle componen mediated by epinephrine. Am J Physiol 1987; 250: E226-9. 